\title{
Teachers as Policy Makers: the Case of Socio - Educative Centres in Andalusia.
}

\author{
Javier Calvo de Mora
}

University of Granada

\begin{abstract}
:
The teacher is an attachment figure and is the curriculum with children from birth to three years old. Literature is reviewed about the nature of desirable practices with infant and toddlers; based on interaction amongst early childhood school, families and community, mainly around the concept of integrated services. In the case of Andalusia model of early childhood education, some contradictions are arising out of the antagonisms both by institutional model as well as teacher profile. The contradictions shall be analysed from two points of view. Firstly, childhood development theory adopted by Andalusia government; and, secondly, data analysis, offer a soft integration of a diversity of education, social and health services aimed to prevent education inequalities, in a context of social and economic deprivation. These dichotomies are especially evident in the spread of responsibilities for early childhood across services of health family and community on the one hand and services of education on the other hand.The problem is that teachers cannot make decisions to accomplish their role as policy curriculum makers. In this context, teachers are "enclosed" in the classroom, so their actions outside of school are undermine by institutional barriers of no integration amongst social, educational, and health services towards compatible objectives.
\end{abstract}

Keywords: Integrative services; teacher as policy maker; Andalusia model of early childhood education

Corresponding author: Javier Calvo de Mora

E-mail: jcalvode@ugr.es

Educational Research eJournal ISSN 2254-0385

(C) Faculty of Education. University of Alicante- Spain

DOI: 10.5838/erej.2012.12.05 


\section{Introduction}

In this paper, I have adopted the commonly accepted definition of early childhood as encompassing the age span from birth to six years: I mean the provision of formal care and education services for children under school age and in the early years of school, where the focus from individual children to a greater awareness of the broader context in which children exist and the influence of culture and context on children and those who interact with them has changed (Hayes, A., Neilsen-Hewitt, C., \& Warton, P. 1999).

This change of approach goes beyond the traditional knowledge base of the field, which was heavily grounded in developmental constructivist psychology and an accompanying broadening of theoretical frameworks informing early childhood research used for this paper (Gallagher, J., \& Clifford, R. 2000; Hart, S., Price Cohen, C., Farrell Erickson, M., \& Flekkøy, M. 2001; Hallam, R., Buell, M. J., \& Ridgley, R. 2003; Bell, M. A., \& Wolfe, C. D. 2004; Tout, K., Zaslow, M., \& Berry, D. 2005; Lee, S. Y. 2006; Fleer, M., \& Kennedy, A. 2006; Hungerford, A., \& Cox, M. J. 2006; Nimmo, J. \& Park, S. 2009; Dalli, C., \& Urban, M. 2010).

From a post - structural perspective, the statement of individuals being isolate and passive people is refused. On the contrary, through social relation, children learn to speak, they create emotions and feelings; form an identity as human beings and to perceive of reality from a point $o$ view. These social relations are strong and supportive in connection to education of every child: the sites where early childhood education narrowly relates teacher work with home and neighbourhood in the following terms:

-At home, parents are the primary teachers and roles modes for young children -through play and dialogic education, care, healthy and safe conditions - they provide a strong and best base related to emotional, social and cognitive learning on the part of constant attention of the parents (Epstein, J. et al. 2000; Stiles, A.; Mount, A. Carey, K. and Holt, T. 2009).

-Besides, from a socio - cultural theory, theorists place the context for learning within the social practices and activity structures that define the characteristics of the learning environment. Social practices, especially language, shape the discourse and scaffold knowledge construction.

The consequences of these theoretical approaches is the teacher as policy maker, whose foundations are based on a balanced and coherent answers to questions related to child status, education, care, interaction with parents, space of learning and other decision they have to take through educational process at early childhood schools period. But a common nexus is required to rationale the logic of the paper. According to Rivas, S. and A. Sobrino (2011):

... the relationship between how teacher educational practices are provided and parental satisfaction and involvement is very close, and its effects are enriching. The initiatives described in this article suggest that strengthening forms of communication among teachers and parents is an excellent way to solve problems and to maintain good relationships because teachers are enabled to respond and adapt to parents' demands, while parents are able to express concerns and support the teachers' appropriate ideas and initiatives. As a consequence, the importance of the role of teacher in informing parents about the children's behaviour and abilities and helping them put their expectations about the children in perspective should be reinforced and valued in any protocol assessment for determining quality. At the same time, structural supports available to help parents accomplish their goals as the primary educators of their children should also be safeguarded. (p. 280) 
Furthermore, not only family support influences children development; at neighbourhood level, the concept of teachers as policy makers is used as umbrella rationale to cover possibilities of teachers' profile in early childhood schools. In this sense, teachers are concerned about neighbourhood opportunities, mainly social conditions, in which families and children live, to undertake actions in external services and surroundings.

The triangle home, school and neighbourhood constitute the axes of the model of teachers as policy maker. What do we mean Teachers as Policy Maker (TPM)? My definition of TPM is a professional co-constructor of knowledge and culture focus on cognitive development, but also economic, social and emotional engagement, by several actions: critical reflection; shared inquiry and dialogue, and understanding the contemporary diversity of children lives. A teacher who is doing policy decisions to interrelate the three spaces of children life into a sustainable way to achieve the aim of early childhood education is primary step of formal education system: culture education.

Fig. 1

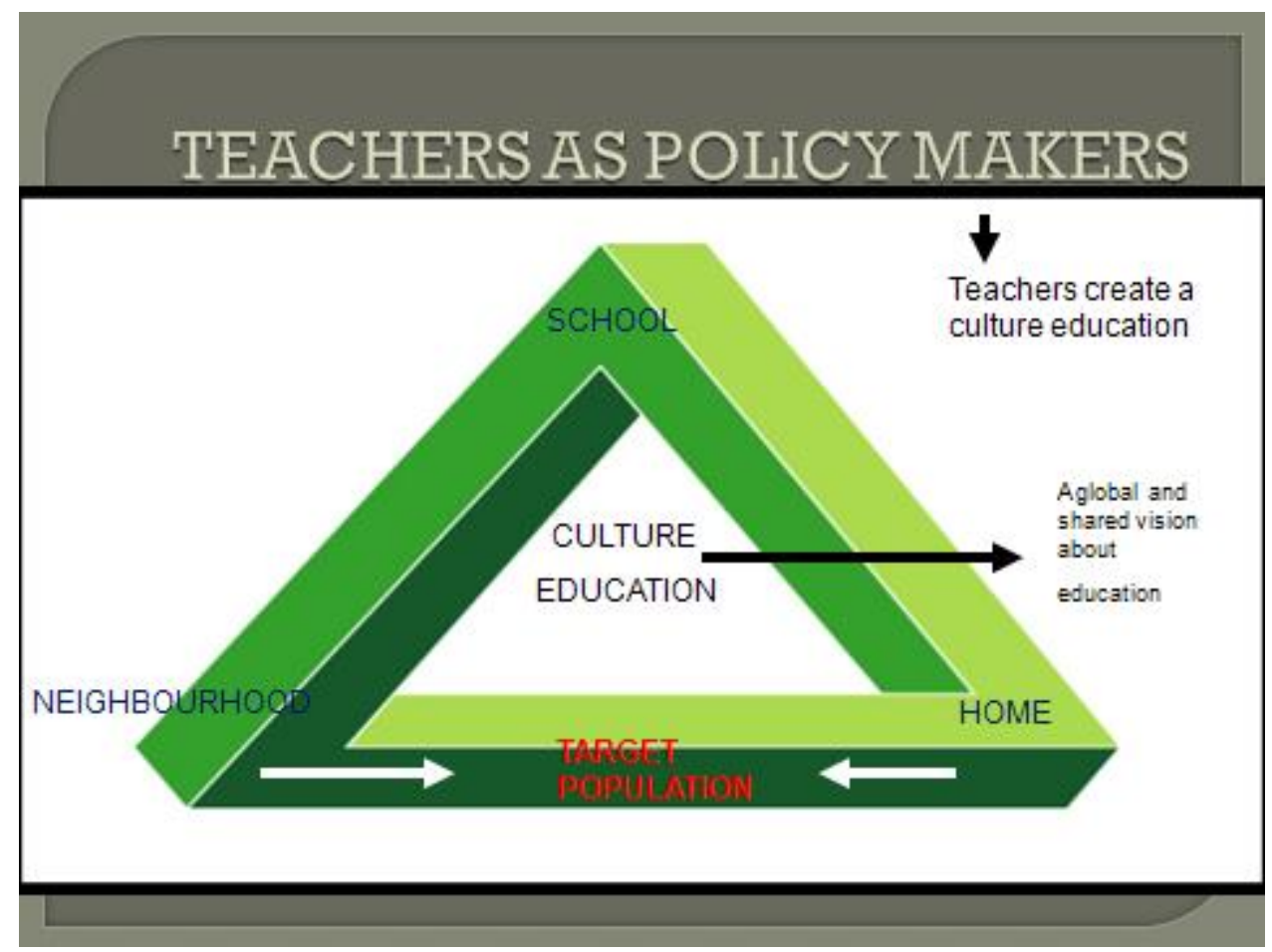

Culture education is a global and shared vision about early childhood education, dealing with political decisions, which transform services into an integrated offer to sustain a coherent approach to readiness aimed to a target population at risk of school failure.

In this paper, readiness is defined as the preparedness of young children to enter kindergarten and the preparedness of schools to receive young children into public educational settings. Current school readiness trends take a broad approach to preparedness which looks at contributions of communities, schools, and families to children's readiness to learn across educational and cultural domains.

Several reasons inspire me to approach an organisational approach to achieve this TPM to accomplish readiness as well as sustainability of family support. 
Sustainability in of the family education support means valuing and enhancing positive perception of school education on the part of parents across children schooling periods by getting involved in cultural and educational matters.

\section{Andalusia model of Early Childhood Education.}

The overall Andalusia policy (Junta de Andalucía. 2008) of an early childhood program is dependent upon several factors: quality staff, suitable environment, appropriate grouping practices, consistent schedules, and parent involvement. Decisions about these factors are often made early in the planning and while organising the process for an early childhood program. These decisions have important ramifications because they affect the child, the family, the classroom, the school, and the community, across five policy guidelines:

\subsection{Continuity in children's days.}

The central actor in this policy statement is the teacher as creator of a suitable environment to educate and take care of children from birth to six years olds. Early childhood teachers also need adequate time to focus on and interact personally with children and their families.

\subsection{Facilitate access to local services.}

A second factor in planning for effective early childhood Andalusia program is a suitable environment for the learning styles of young children. What aspects are included in this concept of suitable environment?

-The physical environment: This includes the classroom setting as well as the outdoor spaces. An appropriate indoor environment can be created by subdividing a large classroom into learning areas or workshops (rincones). The outdoor spaces are also important in early childhood programs;

- A second factor in planning for effective early childhood program, proposed by Andalusia government, is effective grouping practices. Particularly, children are grouped by grade-level according to age;

- Another factor enacted by Andalusia government is to note the importance of consistency in the daily routine:

Children feel more secure when they can predict the sequence of events and have some control over their environment. In addition, predictability provides children with a rudimentary sense of time, as they begin to learn what comes first in the day, second, next, and last. A consistent schedule also helps build trust in the environment. (Decree 428/July 29 ${ }^{\text {th }}$, 2008: 37)

-A final factor in planning for effective early childhood programs is parent involvement. The Regional Government of Andalusia recommends that early childhood staff should form a partnership with parents through home visits, frequent communication, and a welcoming attitude towards volunteering and classroom observation.

Andalusian Government believes that good teachers, and suitable environment, quality of early childhood Education are assured and give credit to other policies decided around Europe, whose hope of proper infant schooling would make a positive impact on a wide view of children's learning (European Commission 2009) with a common agreement in interrelating families, communities and schools. Also, current literature advocates for this interaction:

"These can be provided through
arrangements involving families,
communities, or institutional programmes,
as appropriate." (Robert G. Myers,
(2004:8).




\subsection{Multidisciplinary team working together.}

The key of this policy model is teachers engaging with, and encouraging, participation from children and their families from diverse cultural groups. This is especially important because this model of ECEC is put into practice at deprived zones holding on by strong social policies. The main professional object of teachers is to keep in mind individualised learning to act as intersubjective partners who optimise opportunities for learning and child development and foster every child's capacity to learn. These actions of interaction, co-operation and collaboration are a voluntarism matter into Andalusia policy framework of ECEC. Furthermore, community actors in the field of health, social service, community development, and social workers are not regarding school as focal point in their everyday job.

\section{Policy problem of the Andalusian model of Early Childhood Education.}

In this paper I introduce the Andalusian policy model of ECEC-Centros Socioeducativos- whose target population is from birth to three years of age living in poor conditions; it incorporates services from children's centres and community responsibility mentioned above which evidence some interconnected strategic problems:

-The problem of these ECEC services is accessing and participating of lower class as well as immigrants' families, since family is both a social and cultural target of the ECEC. ECEC services in Spain contain a large proportion of children of low socio economic level as well as immigrant families who form an important cohort in terms of policy
-Family, as well as community, does not play an active role in the social development of the policy of ECEC. And this weak involvement at schools is a pitfall in order to ensure meaningful, relevant, and respectful learning experiences for each child and family. There is a recognition that families need to play a more important role in order to ensure meaningful, relevant, and respectful learning experiences for each child and family.

The problem of the effect of these services on the target population -family of childhood- is the reproduction circle of marginalised families whose children obtain low educational results characterised for underprivileged families who received a lower standard of education and learn less, so becoming, as Bourdieu and Champagne (1999) pointed out, the "segregated from within"; that is to say: these early education services should affect family culture towards collaboration and cooperation, at home, into educational matters (Gardner, 2003; Anderson-Butcher, D. and Ashton, D. 2004; Horwath, J. and Morrison, T. 2007; Beaty, C. 2011) The political strategy is to help to solve this situation of reproduction cycle of the new children generations, by empowering the education based on community.

\section{Analysis of the policy problem.}

A policy analysis, of the Andalusia model, gives perspective to teachers in autonomy to manage as well as decide with the social and cultural agents and elements enacted by Regional government at this level of education policy. In this sense, teachers have to fulfil a huge variety of roles (one- man band ) with different social and economic agents: as parent educator; social worker 
collaborator; social paediatric assistant; local leaders' follower and other actions related with a central position in the network of integrated services. This paradoxical situation is not solved by Regional Government: to accomplish the requirement of individualised learning, teachers must interact with other agents, but they do not have legal authority to manage a stable framework of collaboration and cooperation in the context of community of every child, as showed in the figure 2.

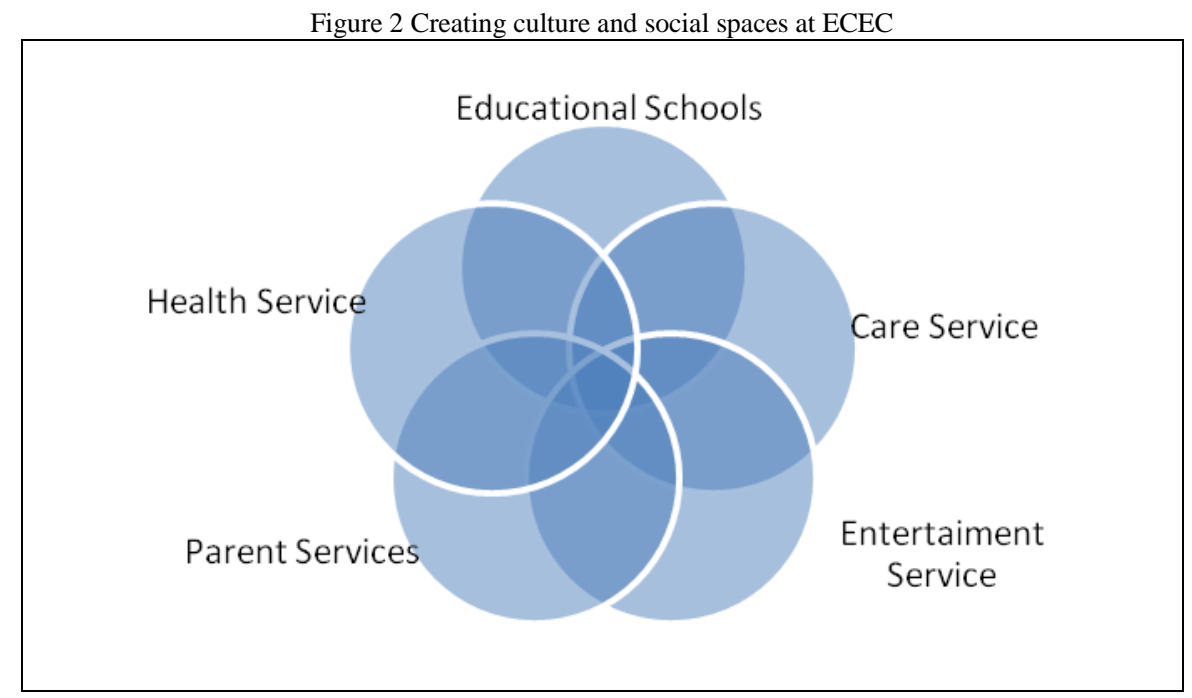

This space of interactions amongst a diversity of services, in early childhood education, has the aim to develop and to solve problems in social and emotional areas, where the teacher's role is to expand and to enrich the content of activities by increasing interaction amongst peers and adults in a balanced and sustainable way (Asokaraj, R. 2011). In other words, schools are not isolated spaces, but part of integrated services aimed together to child development. Carl Corter and Janette Pelletier (2010) state:

There is an increasing policy interest around the world in building early childhood services systems that are universal and integrate a way of strengthening the effectiveness and equity of early childhood services. In addition, integration is conceptualised as the creation of a single entity, with common policies and core staff team.

Other scholars (Howard, J. and Morrison, T. o.c.:58) have defined integrated services in the following terms:
Integrated services are characterised by a unified management system, pooled funds, common governance, whole systems approach to training, information and finance, single assessment and shared targets.

Figure 2 acknowledges social and cultural participation headed by a diversity of population has proven to be an effective part of school improvement strategies and improves pupil and staff well-being and confidence through the identification of the strengths of current practice as well as areas for improvement, but the institutional problem is to reflect what parents' profile participate and collaborate at schools. So, parents with low education expectations and weak trust at school determine life conditions improvement which is less inclined towards participation at kindergarten and day care schools (Halle, Tamara G.; Kurtz-Costes, Beth and Mahoney, Joseph L. 1997, Goddard, Roger, D. 2003). It must consider an integrated services 
model with the double object of raising parents' educational expectations and to increase trust at schooling process aimed to improve personal and livelihood conditions (Wood, D., Kaplan, R.C. and McLoyd, V. 2007), but obviously depending on community development and the resources available to achieve a holistic policy of integrated services for children development.

\section{Case Study.}

The study was initiated in 2010 because I was interested in knowing how deprived communities could improve education perception through a quality programme of early childhood education. To deal with this purpose, I designed an inquiry model according post structuralist theory as well as socio cultural theory.

On the other hand, data collecting follows a strategy of describing effects of the Centro Socio Educativo de Almanjayar: A relation between the output and the outcomes of the system designed by Regional government to Centro Socio Educativos is the chosen strategy of policy analysis according a well know tendency of policy analysis (Sammons, P., Sylva, K., Melhuish, E. C., SirajBlatchford, I., Taggart, B. and Elliot, K. 2002; Mac Naughton, G.M. 2006; Sammons, P. et all 2007) that suggests describing results to subsequently build on a critical interpretation of facts.

The case study was carried out in the context of multiethnic Almajayar district (Fernández Castaño, F. 2010; Jiménez Bautista, F. 2006) This district is situated in the north of Granada city (Spain) and is identified by a shortage of resources such as housing, equipment, cultural minorities, unemployment and low employment qualifications experienced by immigrants, home and genre violence, weak health, dropping out of school and school failure.

The program of Centro Atención Socio Educativo de Almanjayar is intended for children who have been classified at risk for school failure as indicated by high levels of poverty, illiteracy, unemployment, limited Spanish proficiency, or other need-related indicators, such as the school district's rate of dropouts, retention, truancy, teenagers pregnancies and homeless students, high rates of infant mortality, birth trauma, low birth weight or prematurity, and high rates of child abuse and neglection.

According to the foundation of the Centro de Atención Socio Educativa de Almanjayar, the policy declaration tries o answer those questions in upcoming terms of needs of children population in this community:

-Children need to be socially and emotionally ready for school. This is one of the most important areas of readiness for children. Children need to be able to cooperate with their peers in group situations and activities. Children also need to be able to control their impulses and be able to relate to non-family authority figures;

-Children need to have acquired motor skills. Motor skills include large muscle activities necessary for walking in a straight line and throwing a ball. Motor skills also include small muscle skills such as drawing, colouring, cutting, and beginning handwriting;

-Children need to be cognitively and intellectually ready for school. Intellectual readiness is a term used to describe the learning skills a child needs to make a smooth transition into centro socio educativo. These skills include knowledge of colours, numbers up to 10 , at least some of the letters of the alphabet (e.g. particularly the letters in his/her name), and shapes. Other skills 
that children need are the ability to assemble simple puzzles, answer questions about his/her environment (e.g. how many legs does this spider have?), and understand similarities (e.g. how are an apple and an orange alike?), differences (e.g. how is an apple different from an orange?), and opposites (e.g. ice cream is cold, coffee is hot);

-Children need to be curious and eager to learn. Our children will be most successful if they learn how to ask questions, think independently, and be creative. Our children need to be curious about the world, interested in how things work, and know how to creatively approach problems. So, if your child asks you a question like, "Do mosquitoes sleep?", resist the urge to answer (you may not know anyway!) or to give them the answer right away. Instead try asking them, "What do you think?" or "Where do you think we could find the answer to that question?" By doing this, you are encouraging them to think for themselves. This also helps build a child's self-esteem!

\subsection{Data Collection}

Data scheme come from different sources. First at all, the review of international and national integrated service models for young people in the preadolescent and adolescent years (Schmidt, H., Burts, D. C., Durham, R. S., Charlesworth, R., \& Hart, C. H. 2007; Moore, R. W. et all. 2011) described in the report Evaluation of Victorian children's centres, which Figure 3 describes, shows a synthesis of five steps of integrated service process, whose basis is included in the rationale of sources above mentioned.

Secondly, in this construction process of integrated services, child, family and community participation is actively promoted and supported by regional policy on CSE (Sevilla Moreno, D. 2001; Junta de Andalusia, 2007; Junta de Andalusia, 2008). This step becomes central to the development process of this model of CSE organisation, due to balanced care and education dimension of the identity of this schooling period.

Figure 3. Cycle of integrated service process

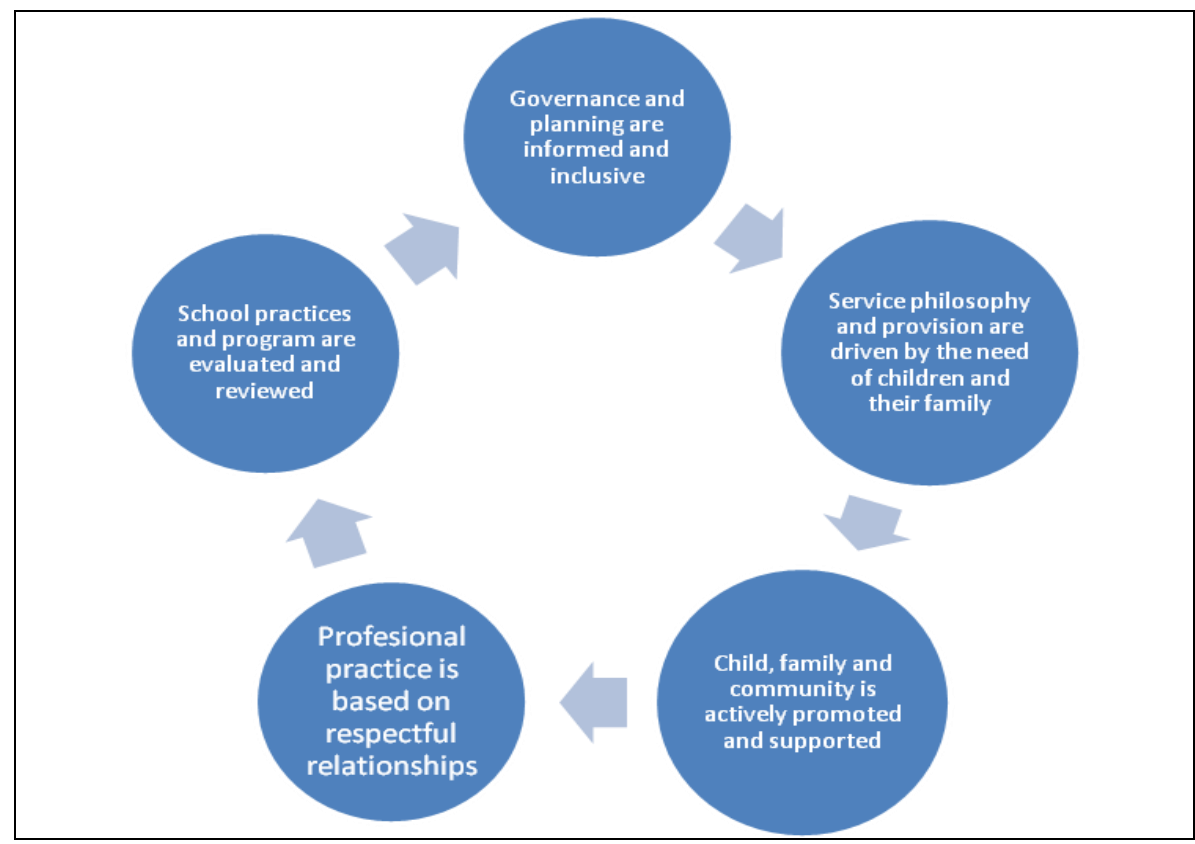

On the one hand, care is a primary action to provide hygiene routines, healthy well being, and recreation supported by play and game activities. Education, on the 
other hand, promotes social and emotional development, school and parental continuity actions, and community involvement in the responsibility of delivering cultural, social and health services. There is strong evidence that high quality pre-school provision that integrates childcare and education is associated with improved cognitive and behavioural outcomes for children. Generally, parents are positive about integrated provision in the early years, valuing the range of support they can access in one place and in the improvements in their parenting skills (Canadian Council on Learning, 2009).

I have chosen twelve outputs disposed in the establishment dated back in the policy declaration of the Centro Socio Educativo de Almanjayar district:

-Service coordination;

-Culture of local collaborative practice;

-Culture of services coordinator activities;

-Education and health services;

-Health and mental health;

-Family support services;

-Community social welfare services;

-Social and community leaders.

As respect the outcomes, I have selected the eight stated by Regional policy to families on ECEC from birth to three.

The outcomes selected are:

-Holistic integrated program;

-Accessibility to service;

-Rates of users, beneficiaries and members of services;

-Physical, social, emotional well-being of families;

-Responsibilities at home;

-Motivation of family to achieve emotional competence;

-Child development of self concept;

-Prevention of teenager pregnancy.

5.2 Outcome analysis.

According to the theory of integrated services, we need a sustainable and balanced cooperation amongst schools and community services to accomplish individualised learning on social justice for poor children population. The hypothesis is an optimal dealing, with a diversity of actors who are coordinated by teachers as policy makers of projects and other actions to successful achieving aims, and objectives, of the school studied in this paper.

For this reason, the preliminary data implies a diagnostic of use of services provided to enhance social, educational and healthy opportunities of the population of the Almanjayar district. In other words, the Centro Socio Educativo de Almanjayar was designed to build up the material, social and cultural resources directed to children on the basis of equity and promotion of a good childhood in the present, and not predominantly on the basis of economic efficiency.

The policy guidelines of Socio Educative Centre is not located in a single service with a variety of functions, but different services established in the same area, according to a regional program to areas at risk of social and cultural exclusion, where education plays an important role, according a general policy framework:

-Services have to provide information about available resources;

-Parents will be better informed about available services and facilities;

-Families will find it easier to access early childhood and family support services;

-Referral of children with health or developmental problems to specialist services will be more prompt;

-Children's health and developmental problems will be diagnosed earlier.

The strategy of these policy guidelines is to describe routines of families on health and education matters, which must include a commitment to improve universal access to essential healthcare. The rationale of this analysis is to study synergies that exist between the various 
health and child development programs delivering efficient and effective health and educational services; while care/education and health are two intertwined actions both directed to children wellbeing, and also an indicator of collaboration between different professionals with the same target population.

The result is 62 parents who answered the questionnaire. They represent only 45 percent of families, parent and tutor legal of the school children population of the Centro de Atención Socio-Educativa Almanjayar, which is daily open from 7 am to $7 \mathrm{pm}$, except weekends.

A questionnaire was prepared and either given or mailed to parents. In the first part of the questionnaire, demographic questions were asked, including gender, nationality, family income, level of education for both parents, to higher level of one of them. Parents' socioeconomic status was based on the participating parent's education as well as family income and its relation to school participation. Furthermore, parental education and parent choice and information was ranged according participation frequencies. In relation to this, parent choice is good quality education indicator because distinctive features of service types reflect parental needs, e.g. for employment.

The preliminary results are showed in the Table 1.

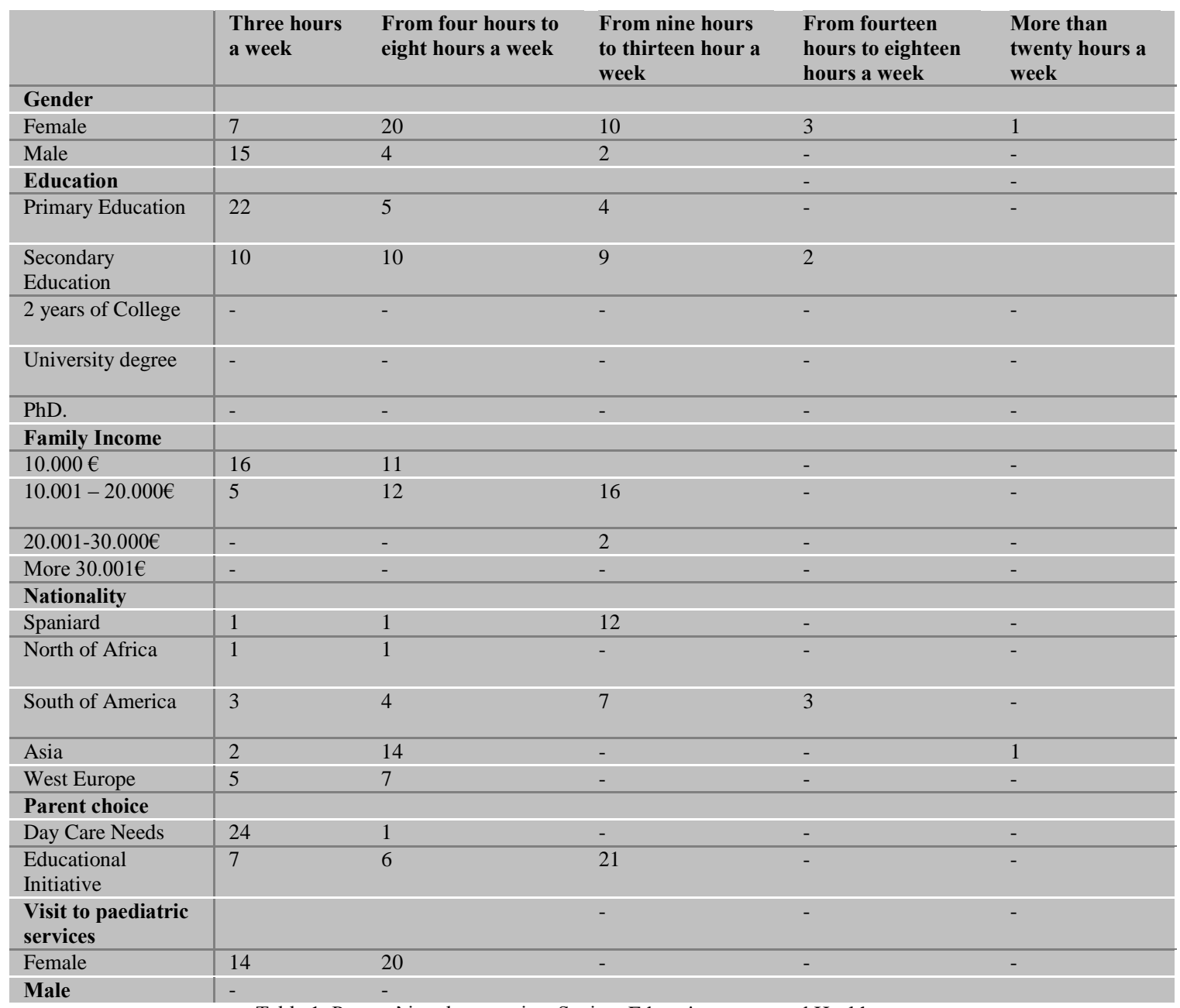

Table 1. Parents' involvement in a Socio - Educative centre and Health centre. Question: How many hours a week do you participate in school and health activities? 
According to this table, we appreciate a positive tendency to become part of the school on the female gender in education, family income and nationality. We suspect that women represent a more interested population participating in schools activities, but more interestingly, women regularly have a job because have firmly pointed out a relation between gender and family income. Women continue to play the traditional role of caregiver to dependent members of the household, often having to attend to the needs of small children as well as those of their longer-lived elderly relatives. In conclusion, Table 1 also indicates a weak interaction between parents and school: more 70 percent have only eight hours per week of interaction; in contrast with the larger number of visits to the doctor headed also by qualified mothers who constitute to the personal connection between children, school and paediatric services. And, what are the interests of the mothers?

\begin{tabular}{|c|c|c|c|c|c|}
\hline Sentence & $\begin{array}{l}\text { Very strongly } \\
\text { agree }\end{array}$ & $\begin{array}{l}\text { Strongly } \\
\text { agree }\end{array}$ & Agree & Disagree & $\begin{array}{l}\text { Strongly } \\
\text { disagree }\end{array}$ \\
\hline Talk about child's progress, interests and abilities & 5 & 18 & 30 & 5 & 4 \\
\hline Talk about child's behaviour & 25 & 30 & 7 & - & - \\
\hline Talk about what the child does at home & - & - & 7 & 15 & 40 \\
\hline Talk about what parent can do to help child's learning & - & 14 & 20 & 25 & 3 \\
\hline Talk about day care timetable and health care & 50 & 12 & - & - & - \\
\hline
\end{tabular}

Parent's educational interest was estimated through content of relationship between teachers and mothers. The results in figure 2 shows that content of relationship between mothers and teachers refer to care and health actions, child's behaviour at school, and actions that children do.

Teacher-mothers contact was mainly informal, made when parents were at the Early Childhood School service. Parents talked to teachers primarily about their own child (Asokaraj, R. 2011). The emphasis on informal contact was an issue for some parents who wanted a set time to talk, such as a parent interview. To complement this information about family interest, a figure with a hierarchy of needs has been drafted.

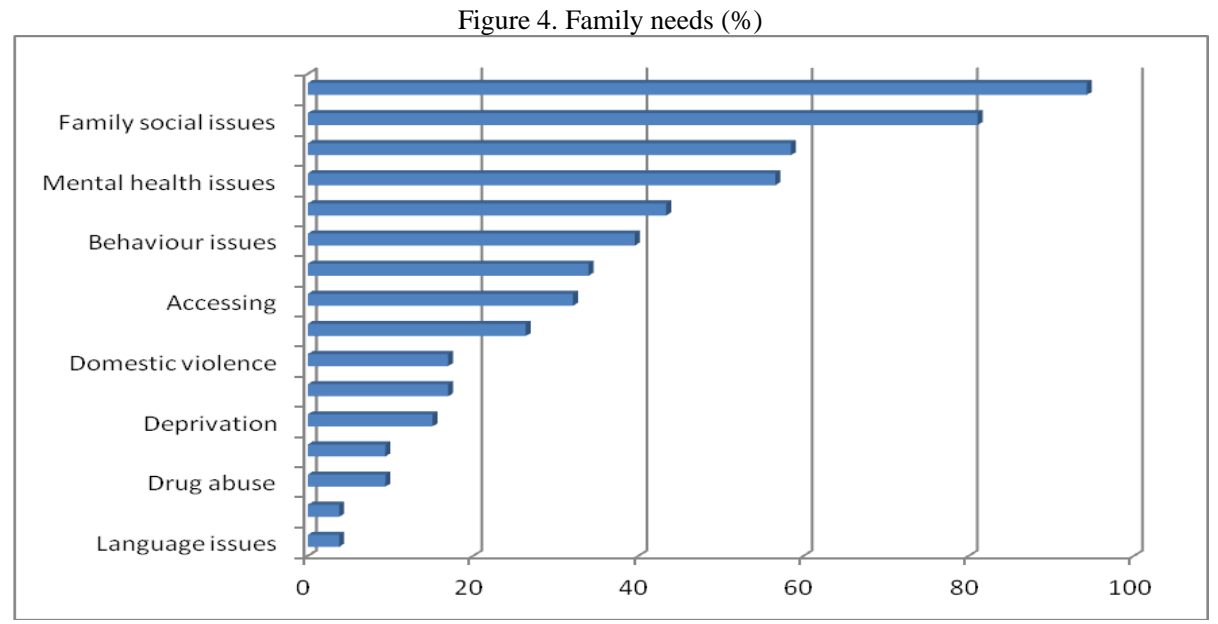


Most parents' needs (mothers' needs Blumberg, R.L. 2007) are related to parenting skills. Usually, parental figures provide support for a child's physical needs, protect them from harm, and teach them skills and cultural values until they reach legal adulthood, usually after adolescence (Wagner, M.; Spiker, D.; and Linn, M.I. 2002): Raising a happy, healthy child is one of the most challenging jobs a parent can have -- and one of the most rewarding. Yet many of us don't approach parenting with the same focus we would use for a job. We may act on our good reactions or just use the same parenting techniques our own parents used, whether or not these were effective parenting skills.

At the figure 4, some distributions of family needs are focused on parenting issues or family support through these services of Early Childhood School in Almanjayar, which is dramatically needed by mothers (Zhang, Y. 2011; Desforges, et all, 2003). Adolescent mothers are less knowledgeable about child development than adult mothers. They generally underestimate social, cognitive, and language functioning and overestimate the attainment of developmental milestones. Compared to adult mothers, teenage mothers perceive their infants' temperaments as more difficult. But these Socio - educative centres no offer opportunities to engage with parents in a family - focussed setting.

Also, figure 4 upholds a culture of consultancy based on asymmetric relations between professionals and customers, where formers give advice according demands asked by clients. In other words, until now, a relation of collaboration and cooperation between users and professional is limited by seeking advice and information about how to educate children at home, perhaps influenced by family expectations.
This table 3, as part of this study, shows how I asked low-income parents of Early Childhood School their own educational and vocational aspirations for their children documented by a shift in the amount of the level parents give to children about their educational and vocational future. The analysis interest of this information is to know parents' concerns about life improvement of their children. This table also is an indicator of trust in the system: their children can improve in the future as well as a constant worry about children situation. As an example, mothers' worry of children health is an indicator of no child abandonment as shown below.

Health supervision and healthy-child visits are a core component of general paediatric care. According to the questionnaire, paediatricians conduct an average of health supervision visits per week with children 35 months old and younger in the Health Center located nearby the school. Mothers mainly, are very worried about healthy condition of their children. Depending on the age, this interest changes from immunisations to toilet training and guidance and discipline. In other words, mother visits are much more frequent to paediatric services than to school.

The paediatric control of family issues is also interesting. During the same period of parents consultation shown in the figure 5 , paediatrics were interested in issues related to alcohol and drug use; parent health, parent emotional support provided by social services, as well as trouble paying for basic needs and community and family violence matter. Paediatric reports inform that alcohol and drug use is the major problem detected during this period. In a second level -parent health and parent support - were issues that parents answered as major difficulties to reach a quality of life. 


\begin{tabular}{|c|c|c|c|c|c|c|c|c|c|c|c|}
\hline Expectations & 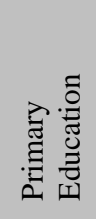 & 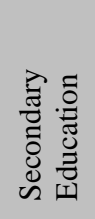 & 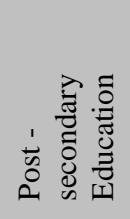 & 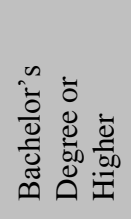 & 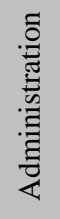 & 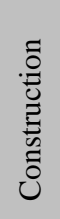 & 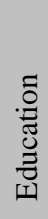 & $\begin{array}{l}\stackrel{0}{\leftrightarrows} \\
\stackrel{0}{\Xi} \\
Z\end{array}$ & 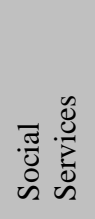 & 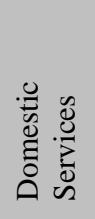 & $\begin{array}{l}\tilde{\Xi} \\
\tilde{D}\end{array}$ \\
\hline Gender & & - & - & - & - & - & - & - & - & - & - \\
\hline Female & 5 & 16 & 14 & 6 & 11 & 11 & 8 & 9 & 2 & - & - \\
\hline Male & 10 & 11 & - & - & 7 & 13 & - & - & - & - & 1 \\
\hline Education & & - & - & - & - & - & - & - & - & - & - \\
\hline \multicolumn{12}{|c|}{ Mother Education } \\
\hline None & - & - & 7 & - & - & - & 2 & 4 & & & \\
\hline Primary & - & - & 3 & 1 & 4 & - & 2 & 4 & & & \\
\hline Secondary & - & . & - & 2 & 7 & - & 4 & 1 & & & \\
\hline \multicolumn{12}{|c|}{ Father Education } \\
\hline None & & 6 & - & - & - & 4 & - & - & - & - & 1 \\
\hline Primary & & 4 & - & - & - & 3 & - & - & - & - & - \\
\hline Secondary & & 1 & 2 & - & - & - & - & - & - & - & - \\
\hline \multicolumn{12}{|l|}{ Family Income } \\
\hline 10.000 & & 7 & 5 & - & & & & & & & \\
\hline $10.000-20.000$ & & 9 & 8 & - & & & & & & & \\
\hline $20.001-30.000$ & & 7 & 11 & 6 & & & & & & & \\
\hline More 30.001 & & & 3 & 6 & & & & & & & \\
\hline \multicolumn{12}{|l|}{ Nationality } \\
\hline Spanish & & 2 & 10 & 2 & 13 & - & 1 & - & - & - & - \\
\hline North of Africa & & 2 & & & & & & 2 & & & \\
\hline South America & & 3 & 10 & 4 & 5 & 9 & 4 & - & - & - & - \\
\hline Asia & & 10 & 2 & & 2 & 1 & 9 & 2 & - & - & - \\
\hline West of Europe & & 5 & 5 & 5 & 3 & 10 & 31 & 1 & - & - & - \\
\hline \multicolumn{12}{|c|}{ Number of children living in the same house. } \\
\hline 1 & - & - & 5 & - & - & - & 1 & 2 & 2 & - & - \\
\hline 2 & 1 & - & 4 & - & 2 & 1 & 1 & 3 & - & - & - \\
\hline 3 & 3 & 13 & 2 & 1 & 10 & 8 & 3 & 1 & - & - & - \\
\hline 4 & 5 & 12 & 3 & - & - & 9 & 2 & 1 & - & - & - \\
\hline More 4 & 9 & 2 & - & - & - & 6 & 1 & 1 & - & - & - \\
\hline
\end{tabular}

Question: what are your expectations about your children both in education and job qualification?

Figure 5. Number of issues in paediatric visits

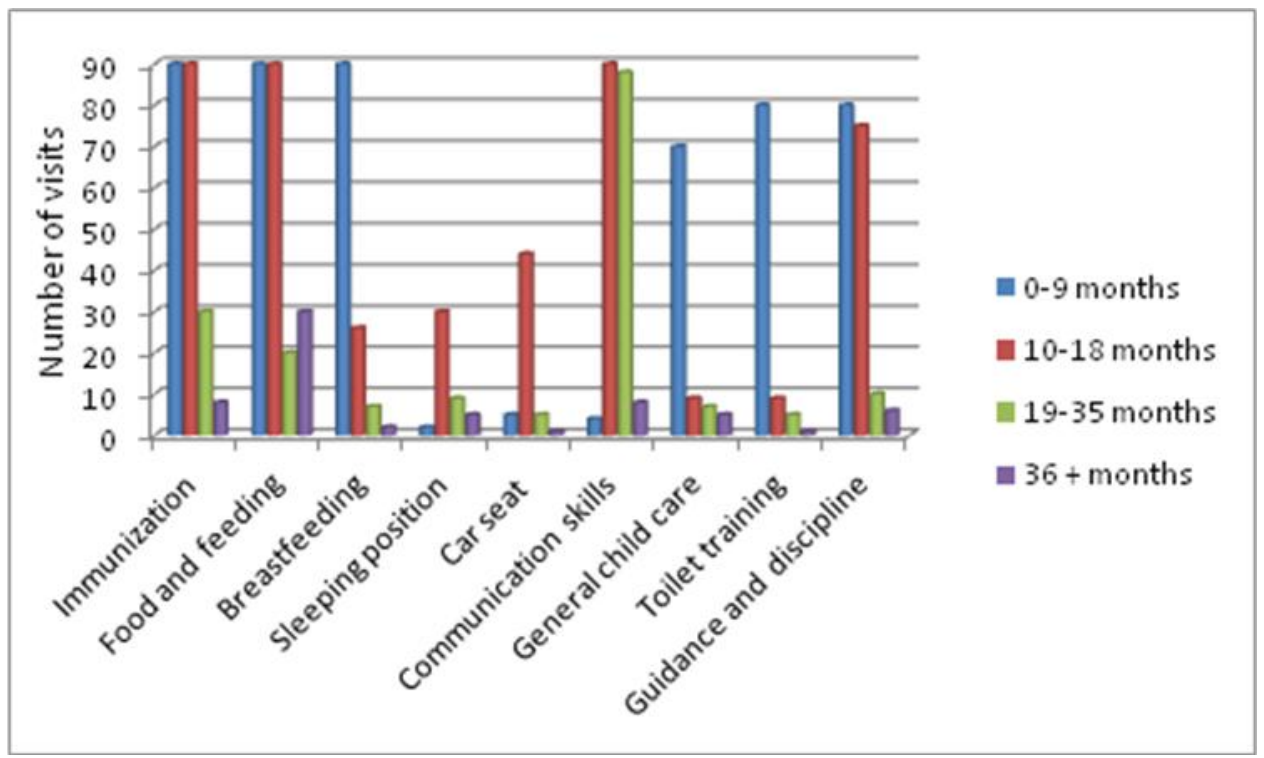




\section{Discussion and conclusion.}

Current literature quoted in the introduction advocates for school as an entity with capacity to fulfil common aims of early childhood education. I conclude that teacher education and training have a mediating effect on positive child outcomes along with a number of other important variables, such as ratios, group size, staff salary, management practices and the "organisational characteristics of the setting", for example, that the evidence overall suggests that group size, qualifications and training can be understood to have: "a positive influence on developmental outcomes for children. Small group sizes and better trained staff are more likely to provide environments for effective child development.

The evidence to support this effective school approach is well documented in the current picture from the prospective longitudinal study in association to the impact of quality of care, and it seems that measures taken when children were between three months and four and a half years indicated positive impact on the later of the children as concerns readiness to primary school. In 2005, the NICHD reports showed that these positive effects had increase over time and some effects from long hours in childcare positively emerged in relation to explicit work habits of the academic culture. Furthermore, a link between high quality childcare and cognitive-academic achievement was found as a strong indicator of school success. This empirical data has risen a policy theory used by government policy makers in standarised terms, for instance:

Higher quality care is associated with more positive outcomes and fewer negative ones (Jacob, 2009; NICHD, 2004);

High quality centre-based early childhood education and care is related to larger cognitive-academic outcomes for children at primary school.

The benefits of routine in high quality early childhood education for all children makes a positive impact adapting children to academic culture;

Parenting quality is also connected to the effects of centre-based childcare;

But this approach goes wrong for several reasons. From my perspective, teachers as policy makers, whose rationale comes from the post structural theory, are parents who perceive education as a cultural "tool" for economic improvement. They are permanently involved in education matters and are inclined towards dialogue with teachers. Other subtle critic to effective school paradigm is inclined to family life and family culture perception: perception of "the child", "the teacher", " the school" and another subjects related to early childhood education, family conditions, collectively share resources raising, well being of the neighbourhoods, and so on.

Paper data shows that educated parents are prone to have a qualitative interactions with teachers at this school. And for other profiles of low educated populations, various studies suggest that community leadership, coordinated services, the participation of stakeholders, and participatory planning processes are all characteristics of successful integrated working (Harbin, G. 1996:70), whose strong points are: facilitating parents' access to education, ensuring child identification of interrelated problems of health, education, housing and parenting, and ensuring effective help to families.

Research also shows those advantages mentioned indicating that many more children derive long term benefits when support is provided to parents in their roles and when family capacity and community connectedness is strengthened. From a psychological point 
of view, this early intervention has to be applied to raising learning's achievement (Marchant, G.J., Paulson, S.E., \& Rothlisberg, B. A. 2001; Ritblatt, S.N., Beatty, J.R., Cronan, T. A., \& Ochoa, A. M. 2002). The institutionalisation of integrated services means bringing together different aspects of child life by coordinating actions of family support, community programs and health.

Also, sustainability of integration is based on project partner at regional and local levels. In this project, kindergarten offered by Regional government are involved and both regional and also local services of family support and community in the scope of social care, culture, environment and health. Additionally, integrated early childhood programs reduce service disconnections, with potential benefits for program quality and equitable access They may also help child and family outcomes and quality of life, by providing more coherent programming for children while supporting parents in their parenting and needs to work or study (Pelletier, J. \& Corter, C. 2006).

In this paperM it has been implicitly shown that teacher do not work in a context of integrated services. They only interact with parents in the context of school as an isolated entity. Why can I do this statement? Teachers are worried about health conditions of the children, they follow up with parents in their demands of caring and education, all duties and responsibilities derived of the foundations, aims and objectives afore mentioned of the Centro Socio Educativo Almanjayar.

The evidence of this isolated teachers action has raised a question of how this Early Childhood School (SocioEducative Centres) has impacted children education, apart from the care actions whose effects are well described by data analysis in this paper. The question was studied through the SelfPerception Profile for Children (SPPC), which is a well known test that consist of 36- item self-reporting scale developed to measure children's domain-specific judgments of their competence, as well as a global perception of their worth or esteem as a citizen. It contains six separate subscales consisting of five specific domains: 1) scholastic competence; 2) social acceptance; 3) athletic competence; 4) physical appearance; and 5) behavioural conduct, as well as a general domain of global self-worth.

Two cohorts of children were tested. One cohort had been beneficiary of socio educative centres and the other one went to a nursery school. The test SPPC was administered to children aged from 4 and 5 years living in the same district of Almajayar who are students of Kindergarten and Primary School. Results are presented in three major sections. Firstly, I describe the component structure of the SPPC in the young children of 4 years olds who went two different ECEC. Secondly, I describe results of child of young children of 5 years old to check if last rates persist.

According these preliminary results, no differences are appreciated between two cohorts of children. Those who went to socioeducative centres present a similar profile as the children of the day care services. That is to say, the type of Early Childhood School organisations seems to have no effect on child development. But this is true and false at the same time. On the one hand, it is true, because SocioEducative Centres in Andalusia do no adopt a policy structure of Children's centres characterised by integrative service. But, on the contrary, is a false appreciation. Children' Centres influence every child's development (Myers, R.S. et all. 2004). 


\begin{tabular}{|c|c|c|c|c|c|c|}
\hline & & $\begin{array}{l}\text { Socio educative } \\
\text { centres }\end{array}$ & & $\begin{array}{l}\text { Nursery } \\
\text { schools }\end{array}$ & & \\
\hline Domain & $\mathrm{N}$ & $\mathrm{M}$ & $\mathrm{SD}$ & $\mathrm{N}$ & $\mathrm{M}$ & SD \\
\hline Social & 70 & 2.98 & 0.66 & 70 & 2.87 & 0.67 \\
\hline Appearance & 70 & 2.75 & 0.70 & 70 & 2.67 & 0.67 \\
\hline Behavior & 70 & 2.84 & 0.73 & 70 & 2.96 & 0.70 \\
\hline Self-Worth & 70 & 3.13 & 0.58 & 70 & 3.00 & 0.64 \\
\hline Athletic & 64 & 3.03 & 0.67 & 58 & 3.14 & 0.65 \\
\hline Appearance & 64 & 2.78 & 0.72 & 58 & 2.78 & 0.68 \\
\hline Behavior & 64 & 2.63 & 0.76 & 58 & 2.88 & 0.75 \\
\hline Self-Worth & 64 & 3.08 & 0.60 & 58 & 2.97 & 0.63 \\
\hline Scholastic & 64 & 3.16 & 0.61 & 58 & 3.20 & 0.61 \\
\hline
\end{tabular}

Table 4: Means and Standards deviations of the self-perception profile subscales by type of ECEC (Data in previous setting?)

In the Almanjayar context, in order to strengthen school influence on child development and to assure educational success, as parents' expectations claims, a governance model founded on asymmetry between beneficiary and experts should be established. And to overcome political strategy from up to bottom, which is contradictory with policy of the community empowerment, whose control resource is headed by regional administration, it becomes a barrier to integrative services.

According to integrative service theory, scholars agree on the need of Democratic governance to enhance an active citizenship policy (Lewis, R. 1999; Print, M. Ornstrom, S. \& Neilsen. H 2000; Beaty, E.E. 2004), whose outcomes are rooted on overarching sense of civic identity, renewed as stable framework bringing about participation and volunteering to integrate people and services through the common purposes of children development.

This polity structure serve to deliberate interested subject for all population involved in each ECEC; and to be truthful this governance structure should be reality in every Andalusia SEC, where would participate parents, local leaders, teachers and voluntary people. Then, according to Dorothy Shipps (2008) through dynamic and process of school democratisation implies:

-Concern about funding integrated services;

-Cultural differences between professionals;

-Clarity about the roles and responsibilities and the purpose of the partnership working;

-Social and cultural leadership;

-Organisational climate based on active participation and valuing diversity;

-Rights and responsibilities;

-Public accountability.

There is a significant amount of material reporting barriers to integrated working and key factors to success (Sloper, A. 2004). Perhaps the key area for development of the evidence base in this context would be successfully feeding the 
learning from such work into future practice rather than continuing to increase the evidence around well established themes.

Unsurprisingly, much of what is quoted to facilitate integrated working is the opposite of what is reported to hinder. For instance, clarity of aims and objectives that are understood by all parties, clearly identified roles and responsibilities, commitment from both senior management and front line staff, strong leadership, good systems of communication and information sharing and structures for joint planning. Joint training, appropriate support for staff, recruitment of the right people with the right skills and shared resources as well as robust monitoring and evaluation of integrated working have also been identified as crucial to the implementation of such working.

Organisational climate has also been identified as a contributing factor to integrated working that support teamwork, flexibility, open flows of communication and promote a shared vision are better able to delivery positive outcomes for clients and provide more integrated services. But some barriers act inhibiting parents access to early childhood schools, for instance:

Parents will not enrol because they do not understand why early education is important; they are unaware of the benefits of preschool or they believe their child is not ready to begin formal education.

Other parents may be apprehensive by sending their children to school earlier than absolutely necessary, having had negative educational experiences while growing up

Some families may not have all the facts about Preschool for All. They may think they have to pay for its services or that they will lose their child care subsidy if they enrol their child. In this service analyse only 54 percent of population from birth to 3 years are enrolled in these services (Statistics Service of Granada Town http://www.granada.es/inet/wgr.nsf). And in the population who use the service needs are not accomplished because parenting interested is not carried out at school policy.

Finally, teachers as policy makers at early childhood education seem a plausible hypothesis to prevent unequal opportunities in this initial education experience, mainly in the case of poorest population, for two main reasons:

1. An integrated offer of education leading by teachers as policy makers are more likely to fully develop cognitive, language, emotional and social skills; to grow up healthier; and to have higher self-esteem. Each one of these areas is crucial to our well-being as adults; our experiences in early childhood truly shape who we ultimately become.

2. Other forms of organisation of education are needed. Like the Madhav Chavan project or similar ones, traditional education culture or traditional schooling in which constancy strengthen family support by helping student to accomplish coursework, strict timetable with rigorous discipline and hierarchy on social relations do not serve to some population with contradictory social and family cultures. This matter was understood by Dr. Charan: a new governance of school based on dialogue and trust with the idea of to pull children towards ways of learning considering emotional and social tendencies of the local children, for instance, like Paulo Freire gives voice to children and to reckon learning progress as significant and important to solve everyday problems as well as to improve well being conditions. 


\section{References}

Anderson-Butcher, D. and Ashton, D (2004) Innovative Models of Collaboration to Serve Children, Youths, Families and Communities Children and Schools_26 (1), pp.39-53. [Abstract] [Back to text]

Asokaraj, R. (2011) Rice, slippers, Bananas and Caneball: Children's narratives of internal displacement and forced migration from Burma. Global Studies of Childhood, 1(2), 120 -128 . [Back to text]

Beaty, E.E. (2004) Creating a laboratory for democracy. Educational Leadership, 61, 75 -78 . [Full text] [Back to text]

Beaty, C. (2011) Integrated Children's Centres. New York: Routledge. [Full text] [Back to text]

Bell, M. A., \& Wolfe, C. D. (2004). Emotion and cognition: An intricately bound developmental process. Child Development, 75(2), 366-370. [Abstract] [Back to text]

Blumberg, R.L. (2007) How mother's economic activities and empowerment affect early childhood care and education (ECCE) for boys and girls: A theory - guided exploration across history, cultures and societies. Paris: UNESCO. [Back to text] [Full text] [Back to text]

Bordieu, P. \& Champagne, P. (1999) Los excluidos del interior, in $\mathrm{P}$. Bordieu (Ed) La Miseria del mundo. Buenos Aires (Arg.): Fondo de Cultura Económica.
[Back to text]

Canadian Council on Learning (2009) The early development instrument (EDI) in British Columbia: Documenting Impact and Action in schools, communities and early childhood development. Vancouver: University of British Columbia. [Full text] [Back to text]

Corter, C. and Pelletier, J. (2010) Schools as integrated service hub for young children and families: policy implications of the Toronto First Duty Project. International Journal of Child Care and Education Policy, 4 (2), 42 -54. [Full text] [Back to text]

Dalli, C., \& Urban, M. (2010a).Conclusion. Towards new understandings of the early years profession: the need for a critical ecology. In C. Dalli \& M. Urban (Eds). Professionalism in early childhood education and care. International perspectives. (pp.150-155) London \& New York. Routledge. [Abstract] [Back to text]

Desforges, Ch. Et all.(2003) The impact of parental involvement, parental support and family education on pupil achievement and adjustment: a literature review. London: Department for education and Skills/Research Report RRR 433. Queen's Prunter. [Full text] [Back to text]

Elias, M. J., Zins, J. E., Weissberg, R. P., Frey, K. S., Greenberg, M. T., Haynes, N. M., Kessler, R., 
Schwab-Stone, M. E., \& Shriver, T. P. (1997). Promoting social and emotional learning: Guidelines for educators. Alexandria, VA: Association for Supervision and Curriculum Development. [Full text] [Back to text]

European Commission (2009) Early Childhood Education and Care in Europe: Tackling Social and Cultural Inequalities. Brussels: Education, Audiovisual and Culture Executive Agency. [Full text] [Back to text]

Fernández Castaño, F. (2010) Desigualdades en el logro educativo del alumnado inmigrante: la emergencia de un Nuevo "cleavage" social. Educación y Diversidad, 4(2), 117 - 136. [Back to text] [Full text]

Fleer, M., \& Kennedy, A. (2006). Quality: Always unfinished business. In M. Fleer (Ed.), Early childhood learning communities: Sociocultural research in practice (pp. 209227). Frenchs Forest, NSW: Pearson Education Australia. [Back to text] [Abstract]

Gallagher, J., \& Clifford, R. (2000). The missing support infrastructure in early childhood. Early Childhood Research and Practice, Spring, 2000. Retrieved November 4, 2010, from http://ecrp.uiuc.edu/v2n1/gallag her.html [Back to text]

Gardner, R. (2003) Working Together to Improve Children's Life Chances: The Challenge of
Inter-agency Collaboration. In Weinstein, J., Whittington, C. and Leiba, T. (2003) Collaboration in social work practice. London: Jessica Kingsley Publishers Ltd. [Full text] [Back to text]

Goddard, Roger D. (2003) Relational networks, social trust, and norms: a Social Capital Perspective on students' chance of academic success. Educational Evaluation and Policy Analysis. 25 (1): 59 - 74. [Full text] [Back to text]

Hallam, R., Buell, M. J., \& Ridgley, R. (2003). Preparing early childhood educators to serve children and families living in poverty: A national survey of undergraduate programs. Journal of Research in Childhood Education, 18(2), 115-124. [Full text] [Back to text]

Halle, Tamara G.; Kurtz-Costes, Beth and Mahoney, Joseph 1. (1997) Families Influences on Schools Achievement in Low - Income, African- American Children. Journal of Educational Psychology. 83 ( 3), 527 - 537. [Abstract] [Back to text]

Harbin, G. (1996) The challenge of coordination Infants and Young Children. 8 (3), pp.68-76. [Abstract] [Back to text]

Hart, S., Price Cohen, C., Farrell Erickson, M., \& Flekkøy, M. (2001). Children's rights in education. London: Jessica Kingsley. [Full text] [Back to text] 
Hayes, A., Neilsen-Hewitt, C., \& Warton, P. (1999). From home to the world beyond: The interconnections among family, care and educational contexts. In J. M. Bowes, \& A. Hayes (Eds.), Children, families, and communities: Contexts and consequences (pp.94 - 114). South Melbourne: Oxford University Press. [Abstract] [Back to text]

Hungerford, A., \& Cox, M. J. (2006). Family factors in child care research. Evaluation Review, 30(5), 631-655. [Full text] [Back to text]

Jaffee, S. R. (2007). Sensitive, stimulating caregiving predicts cognitive and behavioural resilience in Jiménez Bautista, F. (2006) La inmigración marroquí en Granada: su imagen $y$ percepción por los jóvenes granadinos. Estudios Geográficos, LXVII, 261, 549578 [Full text] [Back to text]

Johansson, E. \& White, E.J. (Eds.) (2011, in press). Educational research with infants and toddlers - Voices of our. London: Paul Chapman. [Full text]_[Back to text]

Junta de Andalucía (2007) Ley de Educación de Andalucía. Ley 17/2007 of December 10, 2007. Sevilla: Author. [Back to text] [Full text]

Junta de Andalucía (2008) Decree of early childhood in Andalusia. Sevilla: BOJA, Decree 428, July, 29 ${ }^{\text {th }}$ [Full text] [Back to text]
Junta de Andalucía (2008) Early Childhood Curriculo. August, 26 2008, BOJA, Number 169 Sevilla: Author. [Back to text]

Konantambigi, R.M. (2011) Concerns of Childhood in India. Global Studies of Childhood, 1(1), 79 83. [Abstract] [Back to text]

Lee, S. Y. (2006). A journey to a close, secure, and synchronous relationship: Infant-caregiver relationship development in a childcare context. Journal of Early Childhood Research, 4(2), 133-151. [Abstract] [Back to text]

Lewis,, R. ( 1999) Preparing students for democratic citizenship: codes of conduct in Victoria's "school of the futures". Educational Research and Evaluation, (5) 41 -61. [Abstract] [Back to text]

Mac Naughton, G.M. (2006) Respect for diversity: An international overview. Working Paper 40. The Hague, The Netherlands: Bernard van Leer Foundation. [Full text] [Back to text]

Marchant, G. J., \& Paulson, S. E. (2005, January 21). The relationship of high school graduation exams to graduation rates and SAT scores. Education Policy Analysis Archives, 13(6). Retrieved January 21, 2005 from http://epaa.asu.edu/epaa/v13n6/. [Back to text]

Moore, R. W. et All (2011) . California Integrated Service Delivery. Final Evaluation Report. The complete report of the Phase I 
formative evaluation is available in the projects First Report California Integrated Service Delivery- Phase I Report on California Workforce Investment Board's website http://www.cwib.ca.gov/page/lib rary/ISD\%20Report\%20Master \%20V-1-120710.pdf [Back to text]

Morrison, F.J.; Bachman, H.J. \& Connor, C.M. (2005) Improving literacy in America: Guidelines from research. New Haven: Yale University Press, p. 92. [Full text] [Back to text]

Moss, P., \& Pence, A. (Eds.). (1994). Valuing quality in early childhood services: New approaches to defining quality. [Abstract] [Back to text]

Myers, Robert G.(2004) In Search of Quality in Programmes of Early Childhood Care and Education (ECCE) A paper prepared for the 2005 EFA Global Monitoring Report. [Full text] [Back to text]

Nebraska Department of Education (1992) Overview of early care and education. Lincoln, NE: Office of Child Development, Nebraska Department of Education neurodevelopmentally at-risk infants, Development and Psychopathology, 19, 631-647. [Back to text]

NICHD Early Child Care Research Network. (2000). Child-care effect sizes for the NICHD study of early child care and youth development.

American Psychologist, 61(2), 99-116.
[Abstract]
Nimmo, J. \& Park, S. (2009). Engaging early childhood teachers in the thinking and practice of inquiry: Collaborative research mentorship as a tool for shifting teacher identity. Journal of Early Childhood Teacher Education, 30(2), 93-104. [Abstract] [Back to text]

Parker. J.G., Rubin, K.H., Erath, S.A., Wojslawowicz, J.C. and Buslirk, A.A. (2006) Peer relationships, child development, and adjustment: a developmental psychopatyhology perspective. In Cicceth, D. and Cohen, D.J. (eds) Developmental Psychopathology. Hoboken: John Wiley \& Sons, Inc. [Full text] [Back to text]

Pelletier, J. \& Corter, C. (2006) Integration, innovation, and evaluation in school-based early childhood services. In B. Spodek \& O. Sarracho (Eds). Handbook of research on the education of young children ( $3^{\text {rd }}$ ed. pages 477-496). Matwah, $\mathrm{N}$ $\mathrm{J}$ : Lawrence Erlbaum. [Full text] [Back to text]

Phillipsen, L. C., Burchinal, M. R., Howes, C., \& Cryer, D. (1997). The prediction of process quality from structural features of child care. Early Childhood Research Quarterly, 12, 281-303. [Abstract] [Back to text]

Print, M. Ornstrom, S. \& Neilsen. H. (2000) Education for democratic processes in schools and classrooms. European Journal of Education, (37) 193-210. [Abstract] [Back to text] 
Ritblatt, S.N., Beatty, J.R., Cronan, T.A. \& Ochoa, A.M. (2002) Relationship among perceptions of parent involvement, time allocation, and demographic characteristics: implications for policy formation. Journal of Community Psychology, 30(5) pp. $519-549$. [Abstract] [Back to text]

Rivas, S. and Sobrino, A. (2011) Determining quality of early childhood programmes in Spain: a case study. Revista de Educacion. 355, pp. 257 - 283. [Full text] [Back to text]

Sammons, P. et all (2007) Summary Report on Children's Attainment and progress inKey Stage 2: Cognitive outcomes in year 5 London: Institute of Education, University of London, Research Report No. 828. [Full text] [Back to text]

Sammons, P., Sylva, K., Melhuish, E. C., Siraj-Blatchford, I., Taggart, B. and Elliot, K. (2002), The Effective Provision of PreSchool Education (EPPE) Project: Technical Paper 8a Measuring the Impact of PreSchool on Children's Cognitive Progress over the Pre-School Period. London: DfES / Institute of Education, University of London. [Full text] [Back to text]

Schmidt, H., Burts, D. C., Durham, R. S., Charlesworth, R., \& Hart, C. H. (2007). Impact of the developmental appropriateness of teacher guidance strategies on kindergarten children's interpersonal relations. Journal of Research in Childhood Education, 21(3), 290 - 301.

\section{[Abstract] [Back to text]}

Sevilla Merino, D. (2001) La educación Infantil en Andalucía. Bordón. Revista de Pedagogía, 53(3), 443 - 452. [Abstract] [Back to text]

Shipps, D. (2008) Urban Regime Theory and the Reform of Public Schools: Governance, Power, and leadership. In Bruce S. Cooper; James G. Cibulka and Lance D. Fusarelli (eds) Handbook of Education Politics and policy. New York: Taylor \& Francis, pp. 89 - 108. [Full text] [Back to text]

Sloper, A. (2004) Facilitators and barriers for co-ordinated multiagency services Child: Care, Health \& Development 30 (6), pp.571-580. [Abstract] [Back to text]

Soto, L. Díaz (2005) (ed) The politics of Early Childhood Education. New York: Peter Lang. [Abstract] [Back to text]

Stiles, A. Mount, A. Carey, K. and Holt, T. (2009). On genes, brains, and behaviour: Why should developmental psychologists care about brain development? Child Development Perspectives, 3(3), 196-202. [Abstract] [Back to text]

Tobin, J. (2005) Quality in Early Childhood Education: An anthropologist's perspective. Early Education \& development. 16 (4), 421 - 434. [Abstract] [Back to text]

Tout, K., Zaslow, M., \& Berry, D. (2005). Quality and 
qualifications: Links between professional development and quality in early care and education settings. In M. Zaslow \& I. Martinez-Beck (Eds.), Critical issues in early childhood professional development. Baltimore: Brooks. [Abstract] [Back to text]

UNESCO (2010) Early Childhood care and Education. Regional report. Latin American and the Caribbean. Moscow: Report prepared for the world conference on early childhood care and education, Moscow, September, 2010. [Full text] [Back to text]

Villani, C.J. \& Atkins, D. (2000) Community-Based Education. School Community Journal, 1(1), $121-125$. [Full text] [Back to text]

Vygotsky, L.S. (1978) Mind in society: The development of higher mental processes. Cambridge, MA: Harvard University Press. [Full text] [Back to text]

Vygotsky, L.S. (1987) Thinking and speech, In Reiber, R.W. and caeton, A.S. (eds)The collected works of L.S. Vigotsky: Vol. 1. Problems of general psychology. New York, NY: plenum Press. [Full text] [Back to text]

Vygotsky, L.S. (1998) Child Psychology, New York: Plenum Press, Vol.5. [Full text] [Back to text]

Wagner, M.; Spiker, D.; and Linn, M.I. (2002) The effectiveness of the parents as teachers program with low - income parents and children. TECSE, 22(2), 67-81. [Abstract] [Back to text]

Warner, R. M. (2002). Rhythms of dialogue in infancy: Comments on Jaffe, Beebe, Feldstein, Crown, and Jasnow (2001). Journal of Psycholinguistic Research, 31(4), 409-420. [Abstract] [Back to text]

Weikart, D.P. (2000) Early childhood education: need opportunity. Paris: UNESO. International Institute for Educational Planning. [Full text] [Back to text]

White, J., Ellis, F., O'Malley, A., Rockel, J., Stover, S. \& Toso, M. (2009). Play and learning in Aotearoa/New Zealand early childhood education. In I. Pramling-Samuelsson \& M. Fleer (Eds.), Play and learning in early childhood settings: International perspectives ( $\mathrm{pp}$. 19-49). New York: Springer Publications. [Abstract] [Back to text]

Wood, D., Kaplan, R.C. and McLoyd, V. (2007) Gender differences in the educational expectations of urban, low - income African Youth: The Role of Parents and The Schools. Journal of Youth and Adolescent 36 (4), 417 427. [Abstract] [Back to text]

Yuen, L.H. (2011) Enhancing home school collaboration through children's expression. European Early Childhood Education research Journal. 19(1), 147 158. [Back to text]

Zhang, Y (2011) Mothers' educational expectations and children's 
enrolment. Retrieved November 25 http://repository upenn.edu/gansu_papers/23.

[Back to text]

Zins, J. E., Walberg, H. J., \& Weissberg, R. P. (2004). Getting to the heart of school reform: Social and emotional learning for school success. NASP Communique, 33(3), 3551. [Abstract] [Back to text] 